\title{
WARM MIX ASPHALT FOR AUSTRALIAN AIRPORTS
}

Greg White Technical Manager Airports, Fulton Hogan 2404 Logan Road, Eight Mile Plains, Brisbane, Australia. Email: greg.white@fultonhogan.com.au

doi: 10.1515/ijpeat-2015-0001

\begin{abstract}
Warm Mix Asphalt (WMA) is a viable alternate to Hot Mix Asphalt (HMA) for airport surfacing in Australia. Limited experience with this technology at Australian airports has prevented its acceptance by airport owners and their designers. WMA does have a significant track record in Europe and the USA, where it has been demonstrated to provide significant environmental, safety, quality and construction flexibility benefits. Differences in available binders and the Australian tendency for thinner asphalt layers and less capable materials makes direct extrapolation of experience from Europe and the USA inappropriate.
\end{abstract}

The aim of this paper is to demonstrate the comparative performance of WMA (by foamed bitumen technology) to HMA as an airport surface layer. Comparison between HMA and WMA has been made during a number of projects at Australian airports since 2012. A formal trial was performed at a military airfield as part of a broader project in 2013. A combination of production verification, quality assurance and mix performance tests were used to make comparisons. Subject to ongoing monitoring and performance testing of the military airfield WMA trial section, WMA is now verified as a viable alternate surfacing material for Australian airport runways.

\section{Introduction}

With around 100 airports in Australia having asphalt surfaced runways, the current demand for airport quality asphalt surfacing is around 100,000 tonnes per annum. Simultaneously, airport owners are increasingly demanding environmentally sustainable, safe and technically innovative solutions for their infrastructure.

Warm Mix Asphalt (WMA) is a viable alternate to Hot Mix Asphalt (HMA) for airport surfacing in Australia. However, limited experience with this technology at Australian airports has prevented its acceptance by airport owners and their designers.

The aim of this paper is to demonstrate the comparative performance of WMA to HMA as an airport surface layer for Australian airport runways. Both laboratory and longer-term field performance must both the considered. This aim is achieved by presenting various WMA technologies and the advantages and benefits of these. The limited existing data from WMA usage on Australian airports is presented prior to outlining the trial that was performed on a secondary runway at a major military airfield. Quality assurance and other applicable data are compared for otherwise identical WMA and HMA. Finally an ongoing performance inspection and testing regime is proposed and the suitability of WMA as a runway surface material for Australian airports is considered. 


\section{Warm Mix Asphalt}

WMA is a type of asphalt mix allowing lower production temperatures compared to HMA, which is designed to maintain the desired constructability and post construction properties (Austroads, 2007). Originating in Europe, WMA is manufactured by temporarily lowering the viscosity of the binder. When the asphalt cools to its in-service temperature, the viscosity of the binder returns to that expected for a binder in conventionally manufactured asphalt. Subsequent re-heating to the working temperature must not re-lower the binder's viscosity any further than would be the case for conventionally manufactured asphalt. How this is achieved varies for different WMA technologies. Figure 1 illustrates the typical binder viscosity (and therefore asphalt workability) versus temperature for WMA and HMA based on the foamed bitumen process. The return of WMA binder to HMA viscosity (and therefore asphalt mix stability) occurs at around $100^{\circ} \mathrm{C}$ which is well above Australia's maximum service temperature of $75^{\circ} \mathrm{C}$.

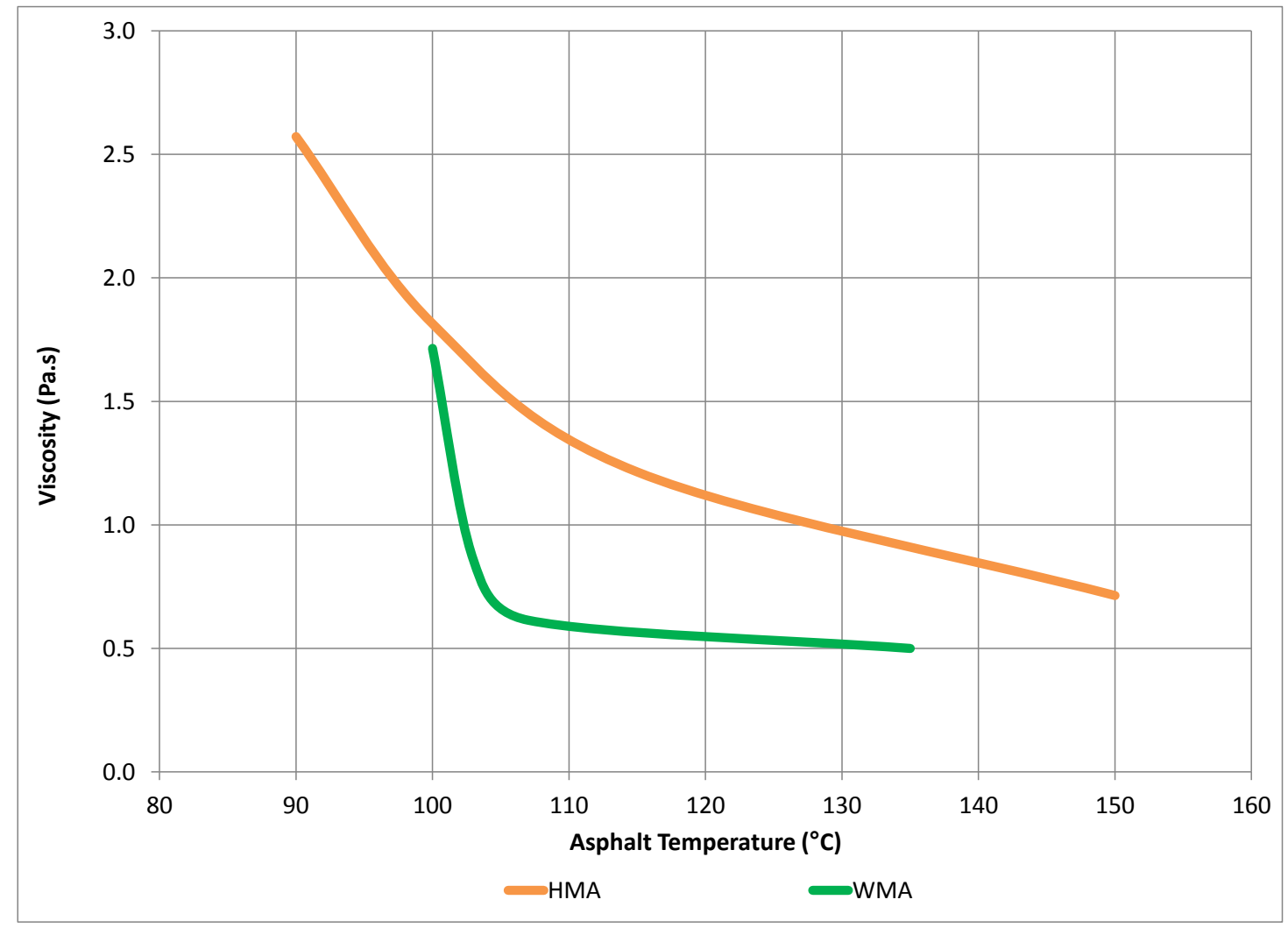

Figure 1 Illustrative Binder Viscosity versus Temperature

WMA generally utilises the same aggregates and binders, as well as the same composition and mix design, as HMA. The asphalt mix design process is not a function of the production temperature or the asphalt plant utilised in the manufacturing process and there is generally no requirement for a different design process or outcome for WMA. WMA and HMA, as well as half-warm and cold asphalts are generally defined by their manufacturing temperature as detailed in Table 1. 
Table $1 \quad$ Asphalt Types and Temperatures

\begin{tabular}{|c|c|}
\hline Type & Manufacturing Temperature Range \\
\hline Hot Mix Asphalt & $160^{\circ} \mathrm{C}-190^{\circ} \mathrm{C}$ \\
\hline Warm Mix Asphalt & $120^{\circ} \mathrm{C}-160^{\circ} \mathrm{C}$ \\
\hline Half-Warm Mix Asphalt & $80^{\circ} \mathrm{C}-120^{\circ} \mathrm{C}$ \\
\hline Cold Mix Asphalt & Essentially ambient \\
\hline
\end{tabular}

\section{Common Technologies}

\section{Methods and Products}

There are a broad range of proprietary products and technologies that can be utilised in the manufacture of WMA. These can, however, be generally categorised into a number of groups or technology types:

- Chemical Additives. Surfactants such as Cecabase.

- Organic Additives. Such as Fischer-Tropsch Waxes like Sasobit, fatty acid amines like Licomont BS 100 and Montan Wax.

- Foamed Bitumen processes. Using synthetic zeolite (Aspha-min) and the Astec Double Barrel Green technology.

- Two Stage processes. Using a combination of processes such as Low Energy Asphalt (LEA) technology and Warm Asphalt Mixture (WAM) Foam (by Shell).

Table 2 provides a summary of common technologies (Middleton and Forfylow, 2008). Due to their popularity in Australia, Sasobit and the Astec Double Barrel Green technologies are described in more detail in the following sections.

Table 2 Common Warm Mix Asphalt Technologies

\begin{tabular}{|c|c|c|c|}
\hline Process & Company & Additive & Production Temp $\left({ }^{\circ} \mathbf{C}\right)$ \\
\hline Sasobit & Sasol & Yes & $20-30^{\circ} \mathrm{C}$ reduction \\
\hline Aspha-min & Eurovia, PQ & Yes & $20-30^{\circ} \mathrm{C}$ reduction \\
\hline Evotherm & Mead-Westvaco & Yes & $85-115^{\circ} \mathrm{C}$ \\
\hline Low Energy Asphalt & LEACO & None & $<100^{\circ} \mathrm{C}$ \\
\hline WAM-Foam & Kolo Veidekke & Soft Binder & $110-120^{\circ} \mathrm{C}$ \\
\hline Double Barrel Green & Astec & None & $110-135^{\circ} \mathrm{C}$ \\
\hline
\end{tabular}

\section{Fischer-Tropsch Wax (Sasobit)}

Sasobit is a proprietary product developed by Sosol Wax in South Africa using the Fischer-Tropsch process. It is a long chain aliphatic hydrocarbon containing between 40 and 115 carbon atoms per molecule and having a melting point of $85-115^{\circ} \mathrm{C}$ (Sasol Wax, 2013). Sasobit is supplied in pellet form (as shown in Figure 2) which can be added to the asphalt plant's hot bitumen storage via a purpose-designed feeder unit at relatively modest cost. 


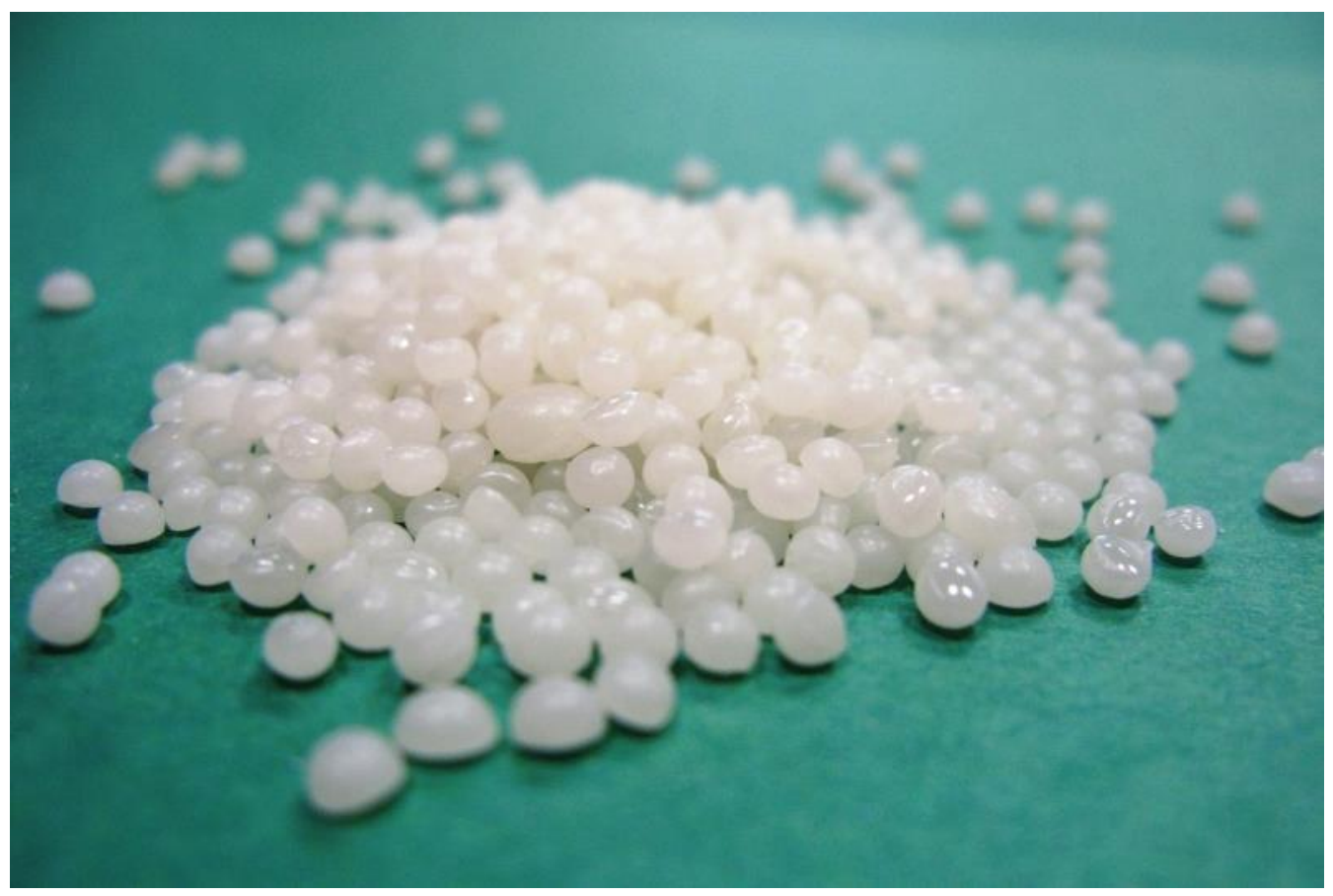

Figure 2 Sasobit pellets

Once the asphalt has cooled to in-service temperatures, the wax molecules crystalise and will not re-soften the binder unless the asphalt temperature is increased to above the melting point $\left(85-115^{\circ} \mathrm{C}\right)$ which is higher than all reported pavement temperatures in Australia (Austroads, 2006). Sasobit's crystalline network leads to improved structural stability of the asphalt at typical service temperatures.

\section{Double Barrel Green}

The Double Barrel Green technology utilises a manifold (as shown in Figure 3) that includes a multi-nozzle water injection system to foam the binder just prior to its addition to the asphalt mixing drum. While this technology was originally developed for Astec Double Barrel asphalt plants, it can now be retrofitted to most models of asphalt plant. The foaming process requires around 1 litre (2\% by mass of binder) of water per tonne of asphalt mix. Some $90 \%$ of this water evaporates during the mixing process. Most of the remaining water is lost as vapour into the atmosphere during the paving and rolling process.

Following a modest initial investment for the addition of the manifold, pipework and water storage tank to a new or existing asphalt production plant, the only ongoing cost for the manufacture of foamed bitumen WMA is the small amount of water added to foam the binder as it enters the mixing drum. Since its introduction in 2007, over 200 Double Barrel Green systems have been installed to Astec and other asphalt plants. 


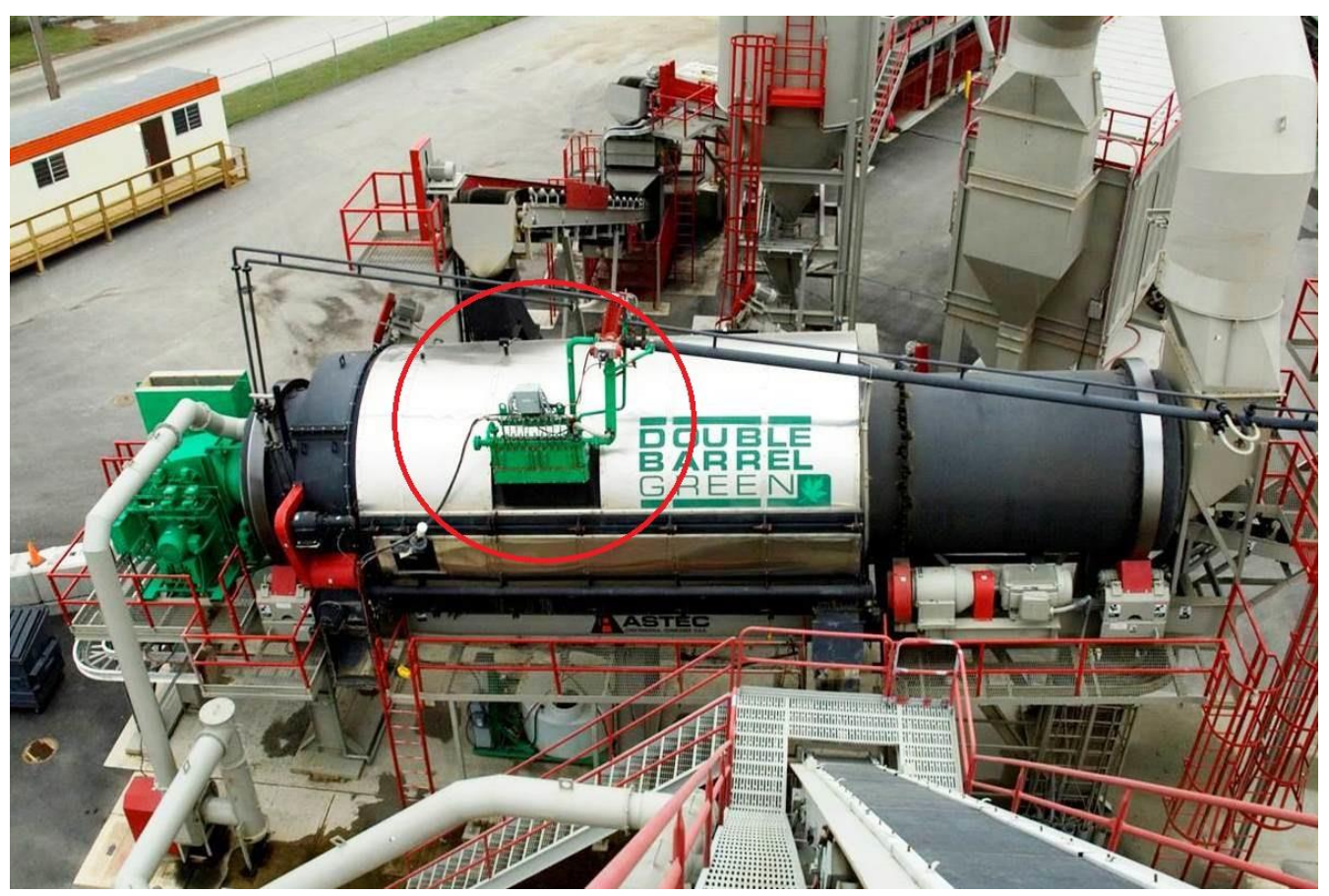

Figure 3 Double Barrel Green System

\section{Advantages and Benefits}

WMA has numerous advantages over traditional HMA. Demonstrated performance over 20 years (EAPA, 2009) shows that these advantages are available to Australian airports with little or no performance risk. While there are related and associated advantages to the use of WMA, the primary advantages are described as follows.

\section{Environmental}

Airports, like all modern infrastructure, are under pressure from Governments, the community and their owners to reduce their carbon footprint. This stems from both an overarching desire to run the infrastructure in a sustainable manner as well as the desire to be known as an environmentally responsible corporation. WMA represents a significant contribution towards those goals during asphalt resurfacing works.

The standard measurement for generation of carbon emissions is Equivalent $\mathrm{CO}_{2}$ (ECO2). The ECO2 associated with the manufacture and construction of asphalt is complex and varies with changes in (Austroads, 2010):

- The distances from aggregate source to the asphalt plant and to site.

- The moisture content of the aggregates.

- The use of hydrated lime in the asphalt mix.

- The binder content used in the asphalt mix.

- The fuel utilised by the asphalt production plant.

- The asphalt production temperature.

- The efficiency of the asphalt manufacturing plant. 
The haulage distance is generally the shortest distance to a suitable aggregate source. The moisture content can be managed by good quarry practices. The addition of around $1 \%$ of hydrated lime is generally a requirement of the design and specification of airport asphalt in order to stiffen the mastic and reduce the risk of stripping. Burner fuel is generally diesel for mobile asphalt plants where gas lines are not readily available. Fixed asphalt plants are often located adjacent to natural gas mains. Modern asphalt manufacturing plants are designed to be as efficient as possible given the limitations of current technology. These factors are generally fixed or beyond control. The production temperature therefore becomes the primary variable that can be managed to achieve environmental benefit.

The asphalt production temperature is a function of the post-production haul distance to the job site and whether HMA or WMA is being manufactured. HMA is generally manufactured at $160-180^{\circ} \mathrm{C}$ for airport asphalt. Comparable WMA would be manufactured at $130-140^{\circ} \mathrm{C}$. The generation of $\mathrm{ECO} 2$ as a function of asphalt production temperature is shown in Figure 4.

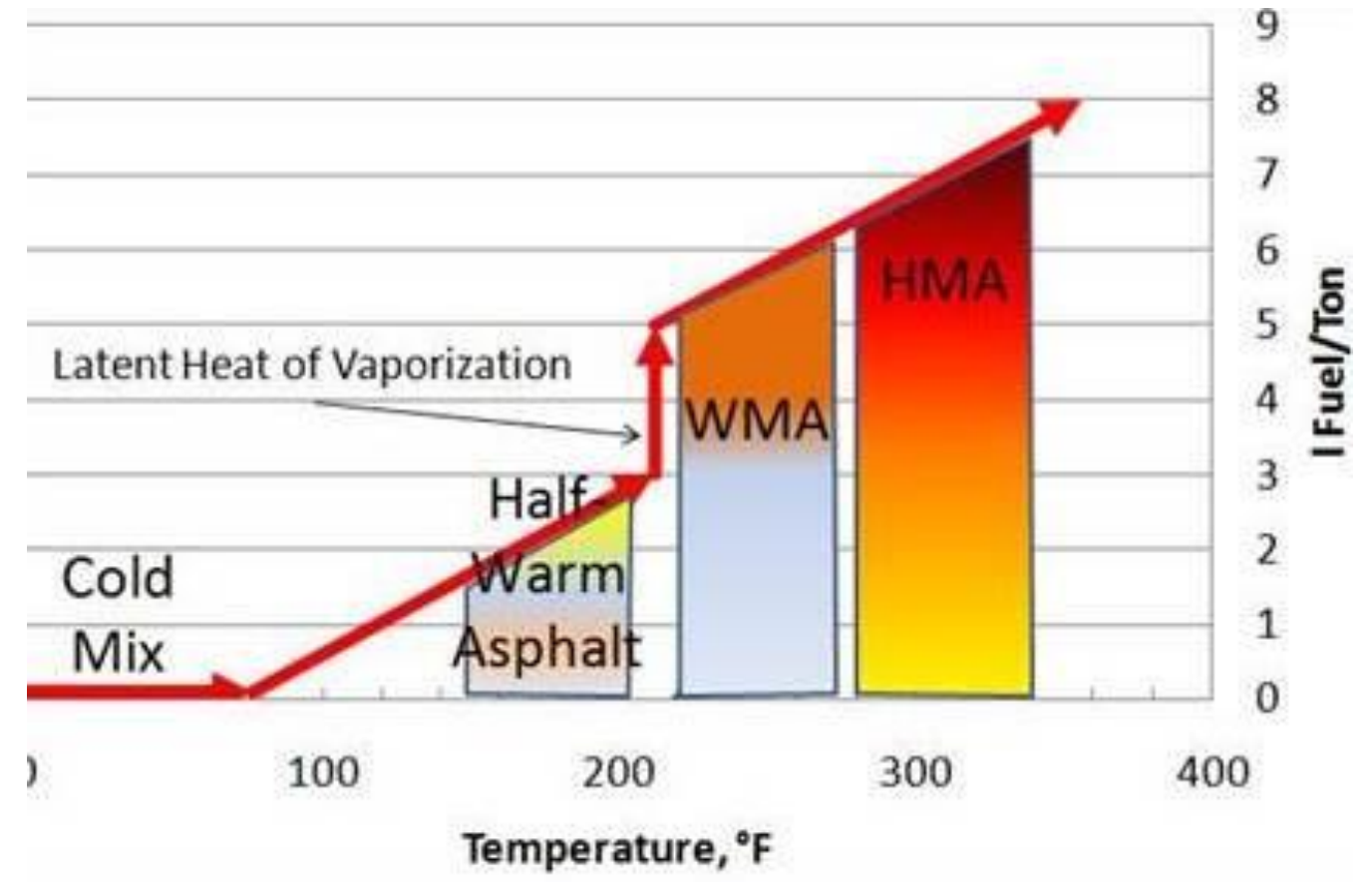

Figure $4 \quad$ ECO2 Generation as a Function of Mixing Temperature

Various studies have found different ECO2 reductions association with WMA. Studies in Europe found a reduction in $\mathrm{ECO} 2$ of about $10 \%$ when the asphalt production temperature was reduced from $170^{\circ} \mathrm{C}$ to $130^{\circ} \mathrm{C}$ (Ripoll and Farre, 2008). Hayward \& Pidwerbesky (2009) reported that WMA can return a reduction in ECO2 of $10-20 \%$. Where Recycled Asphalt Pavement (RAP) was included in the mix, significantly greater ECO2 reductions were reported. WMA and RAP are often considered as associated technologies as the 'aged' binder contained within the RAP and the 'reduced age' of the new binder (resulting from the reduced mixing temperature) combine to give an average binder age similar to that which would result from a new binder exposed to typical HMA production. 


\section{Safety}

Working with hot products presents inherent risks. Bitumen is a high burn risk material, especially when being transferred or stored under pressure. The reduction in burn risk associated with a reduced asphalt paving temperature from say $140^{\circ} \mathrm{C}$ to $100^{\circ} \mathrm{C}$ may be significant.

Fume generation is significantly reduced by even moderate reductions in asphalt temperature. The Emission Exposure Values experienced by staff working with asphalt were found to be reduced by 40-90\% when asphalt temperatures dropped from 160 to $130^{\circ} \mathrm{C}$ (Hurley, 2006). Reduced fume generation is demonstrated in Figure 5.

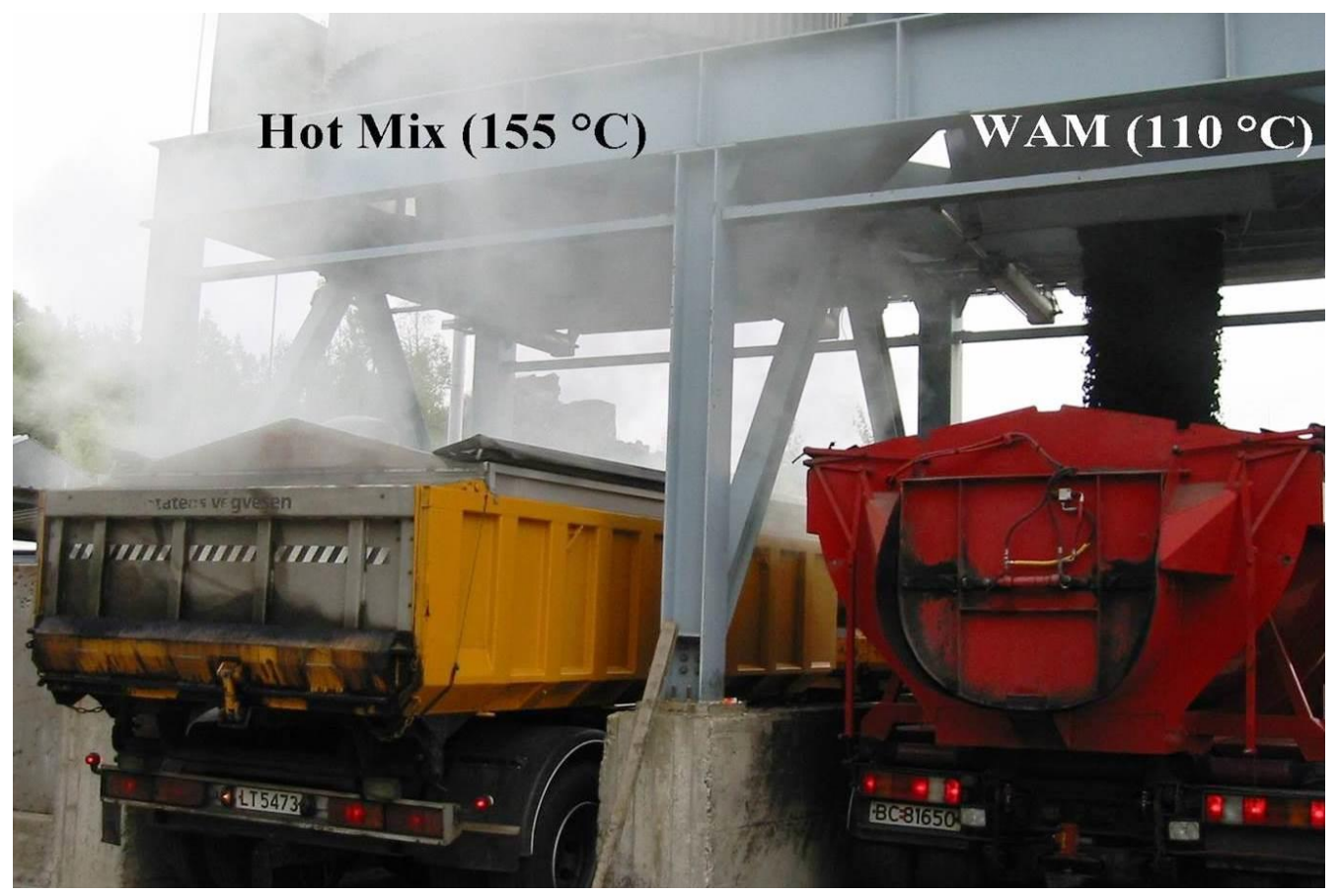

Figure 5 Fume smoke generation by WMA and HMA

\section{Quality}

A finished WMA layer is typically identical in appearance and performance to that of HMA. One of the key advantages is that despite the reduced cooling rate, the lower temperature allows a stable or trafficable temperature to be reached much more quickly. This allows WMA to be utilised in circumstances where thick layers and/or multiple layers of HMA would not cool adequately prior to the next layer being paved and compacted or the pavement being re-opened to traffic.

The other measurable difference between WMA and HMA is the binder aging. The reduced mixing temperature of WMA has resulted in reduced aging and oxidation of the binder during the asphalt production process (Austroads, 2007). This reduces the viscosity and increases the penetration of the binder. As up to $60 \%$ of a binder's whole-of-life aging can be experienced during asphalt production, any reduction in binder aging during the mixing process will result in an extended period until the same degree of aging is reached. If binder aging is the determining factor in an asphalt surface's life (as is often the case for airport runway surfaces which 
experience very low traffic) then the life would be expected to be extended and the period between maintenance overlays increased where WMA is used.

\section{Flexibility}

Asphalt paving is generally performed while the asphalt is between $140^{\circ} \mathrm{C}$ and $160^{\circ} \mathrm{C}$. This allows for adequate workability through the paver and the ability for typical construction equipment to adequately compact the layer. The rate of cooling of the asphalt material is a function of the air temperature and the pavement temperature as well as the asphalt mix's own internal temperature. As the difference between the asphalt's temperature and the surrounding surface temperatures increases, so does the rate of asphalt cooling.

WMA is typically paved at between $110^{\circ} \mathrm{C}$ and $130^{\circ} \mathrm{C}$ to achieve the same workability and compactability as HMA. This reduces the difference in temperature between the pavement and the surrounding surfaces by around $30^{\circ} \mathrm{C}$ and significantly reduces the rate of cooling of the asphalt. This effectively increases the working and compaction time.

Similarly, when being transported long distances to remote sites, asphalt cools at a rate that is proportional to the difference between the asphalt and surrounding temperatures. Again, reducing this rate of cooling provides an increased working time over typically acceptable haul distances. Where longer transport times are required, warm mix technology can be utilised but the asphalt production temperature retained at around $160^{\circ} \mathrm{C}$. This allows increased cooling prior to paving without affecting workability or compactability. This flexibility is particularly useful in regional Australia where many airfields are located 4-6 hours from an established asphalt production plant. It is noted, however that once the minimum compactability temperature is reached, WMA compactability reverts very quickly to that of HMA. WMA provides significantly less 'warning' that this temperature is approaching.

\section{Historical Experience}

While WMA has not yet been embraced by Australian airport owners, it has a track record as an airport surfacing around the world. This experience includes international airports outside of Australia and roads across the globe.

\section{International Airport Usage}

Foamed bitumen technologies have existed since the 1950s. Warm asphalt was first developed as a commercially viable surfacing option in the 1990s in Germany and Norway (EAPA, 2009). In 2003, a number of production and laying trials were conducted in the USA (Kristjánsdóttir et al. 2007) and these expanded to Canada in 2005 (Davidson et al. 2007). Since that time a number of airports in Europe and northern America have utilised various WMA technologies. Examples include Hamburg, Frankfurt and Munich Airports' runways in Germany, Cambridge Airport in the UK, a military airfield in Switzerland, Boston-Logan International Airport's runway in the USA, a US Air Force Base near Anchorage in Alaska and the taxiway and apron at Johannesburg Airport in South Africa.

In 2008, Christchurch International Airport commenced field trials of WMA on their taxiway pavements. The initial trial totaled 141 tonnes to depths of $110 \mathrm{~mm}$. 
Additional trials were conducted with and without RAP over a number of years with all reportedly performing similar or better than surrounding HMA (Hayward \& Pidwerbesky, 2009).

\section{Australian Non-Airport Usage}

While Australia is yet to embrace WMA, trials of various technologies can be traced back to the start of the $21^{\text {st }}$ century including (Austroads, 2007):

- Shell trials with WAM-Foam in 2001.

- $\quad$ RTA NSW trials of Sasobit additives in 2006.

Work performed by the Australian Asphalt Pavement Association and Austroads between 2007 and 2013 has established a framework for the use of WMA in Australia covering field and laboratory evaluation protocols as well as evaluating technologies and their environmental advantages.

\section{Research Methods}

This research was performed by comparison of existing data from a small number of projects where both WMA and HMA were utilised. A full-scale construction trial was then performed side-by-side HMA. This planned trial allowed addition testing to be performed for more detailed comparison of WMA and HMA of the same mix design.

For all comparisons between the HMA and WMA performance, a number of key parameters were selected based on common mix design and conformance parameters. In addition, a number of key performance parameters were also measured. These performance parameters were selected to indirectly assess the comparative degree of binder hardening and moisture sensitivity of WMA and included:

- Resilient modulus. A measure of asphalt stiffness and response to load which is known to be affected by the hardness of the binder.

- Wheel tracking. A measure of shear susceptibility, rutting potential and binder hardening.

- Tensile Strength Ratio (TSR). A measure of moisture sensitivity by comparing the indirect tensile strength before and after water exposure and a freeze/thaw cycle.

\section{Recent Production Comparison}

\section{Adelaide Airport Repairs}

Adelaide Airport repaired a number of areas of distress in an old asphalt surfaced taxiway in 2013. The design for the repairs included two $75 \mathrm{~mm}$ deep layers followed by a $50 \mathrm{~mm}$ wearing course. The asphalt utilised was a typical dense graded airport HMA with polymer modified binder. The works included three patches which were to be performed between 2230 and 0430 , on consecutive nights, prior to reopening to international and domestic aircraft at 0530 each morning. The first aircraft to use the area after the first night was an A330 and this caused 6 to $10 \mathrm{~mm}$ deformations (shoving and rutting) under a single operation. 
During the day, the deformation was rectified between aircraft operations by rolling with a heavy steel drum roller. During the repair work, the pavement surface was noted as still being warm to the touch.

Two subsequent patches were performed the following nights with identical mix but using Double Barrel Green WMA from a fixed asphalt plant and at reduced production temperature. The thicknesses of the repair and timing of the work were similar, but the pavement surface was cool to the touch upon reopening to traffic and no deformation occurred.

The patching work at Adelaide Airport provided limited production data for otherwise identical HMA and WMA produced by bitumen foaming as summarised in Table 3.

Table 3 Comparison of production properties from Adelaide Airport

\begin{tabular}{|c|c|c|c|}
\hline Property & Hot Mix & Warm Mix & Specification \\
\hline Binder Content $(\%)$ & 5.5 & 5.5 & $5.3-5.9$ \\
\hline Flow $(\mathrm{mm})$ & $2.2-2.4$ & $2.3-2.4$ & $<3$ \\
\hline Stability $(\mathrm{kN})$ & $12.8-13.7$ & $13.4-13.9$ & $>11.5$ \\
\hline Air Voids Content $(\%)$ & $4.0-4.3$ & $3.7-4.1$ & $3-5$ \\
\hline Relative Density $(\%)$ & $99.6-99.9$ & $99.4-99.6$ & 95 \\
\hline
\end{tabular}

It can be seen from Table 3 that the WMA had virtually indistinguishable Marshall properties to that of the HMA. The WMA did not suffer from rutting resulting from the inability of the multiple-thick layers to dissipate heat as the HMA did. The surface was inspected some weeks after the work and the only visual difference between the patches was that resulting from the re-rolling of the HMA surface to correct the deformation of the first patch.

\section{Barrow Island Overlay}

In 2012, Barrow Island Airport's runway, taxiway and apron were resurfaced, which included a significant amount of full depth asphalt reconstruction. All works were performed between 2100 and 0600 and made serviceable for the daily Fly-In-Fly-Out operations. Barrow Island is located off the central West Australian coast and provides the land-base for the Gorgon offshore natural gas project (Chevron, 2013). All WMA and HMA were produced in a 170 tonnes per hour mobile Astec Asphalt drum plant with Double Barrel Green foamed bitumen capability.

The work required both $20 \mathrm{~mm}$ and $10 \mathrm{~mm}$ nominal sized asphalt mixes for deep patching and shape correction prior to the $14 \mathrm{~mm}$ nominal sized asphalt overlay. The deep patching included $150 \mathrm{~mm}$ construction in two layers and the surfacing was generally a $75 \mathrm{~mm}$ structural overlay. The asphalt was a typical airport surface mix with polymer modified binder. WMA was proposed in an effort to reduce the risk of rutting prior to cooling to ambient temperature. The resulting patches were of such high quality that the WMA technology was adopted for significant portions of the surfacing layer. The project included a total of 14,000 tonnes of asphalt.

There was no significant difference between the HMA and WMA for the various parameters measured. Table 4 shows the moisture content immediately after asphalt 
production of $10 \mathrm{~mm}$ and $20 \mathrm{~mm}$ nominal sized asphalt's used at Barrow Island Airport. Table 5 shows the average of the relative densities achieved for each Lot. Figure 6 and Figure 7 show the Flow and Stability results for each Lot of $10 \mathrm{~mm}$ and $20 \mathrm{~mm}$ nominal sized asphalts respectively.

Table 4 Moisture contents for Barrow Island Airport

\begin{tabular}{|c|c|c|}
\hline \multirow{2}{*}{ Mixing Temperature } & \multicolumn{2}{|c|}{ Mean Moisture Content of Asphalt at Production (\%) } \\
\cline { 2 - 3 } & $\mathbf{1 0} \mathbf{~ m m ~ N o m i n a l ~}$ & $\mathbf{2 0 ~ m m ~ N o m i n a l}$ \\
\hline Hot & 0.027 & 0.045 \\
\hline Warm & 0.031 & 0.034 \\
\hline Specification (max.) & 0.150 & 0.150 \\
\hline
\end{tabular}

Table 5 Relative densities for Barrow Island Airport

\begin{tabular}{|c|c|c|}
\hline \multirow{2}{*}{ Mixing Temperature } & \multicolumn{2}{|c|}{ Mean Relative Density of Asphalt after Rolling (\%) } \\
\hline & 10 mm Nominal & $20 \mathrm{~mm}$ Nominal \\
\hline Hot & 98.3 & 98.1 \\
\hline Warm & 98.1 & 98.0 \\
\hline Specification (Min.) & 97.0 & 97.0 \\
\hline
\end{tabular}

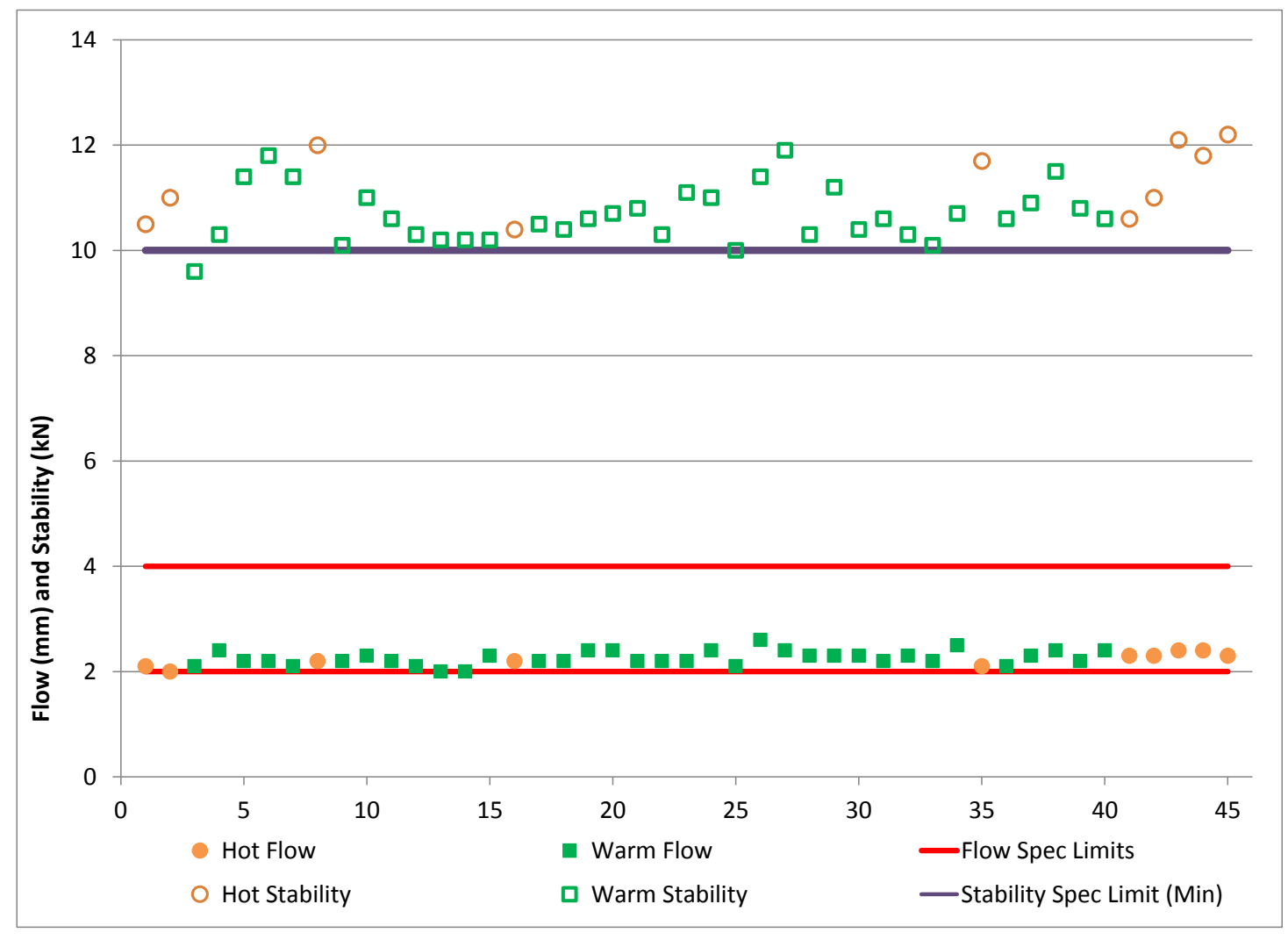

Figure $6 \quad 10 \mathrm{~mm}$ Flow and Stability for Barrow Island Airport 


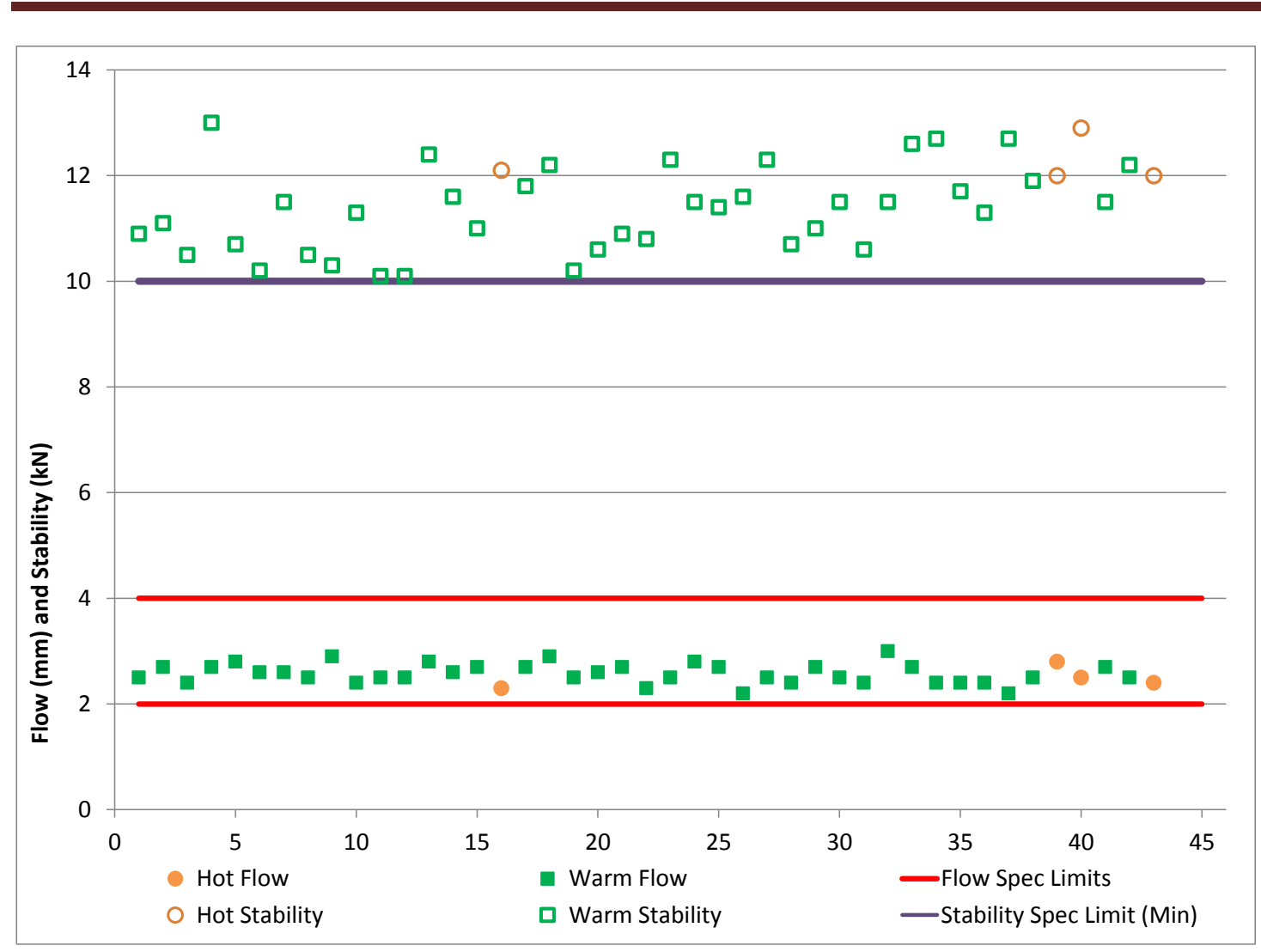

Figure $7 \quad 20$ mm Flow and Stability for Barrow Island Airport

The WMA had, on average, marginally lower Marshall stability, as would be expected for an asphalt with a binder that was exposed to reduced heating and oxidation during the manufacturing process. All Flow and Stability results were compliant across both the $10 \mathrm{~mm}$ and $20 \mathrm{~mm}$ nominal sized mixes for both HMA and WMA.

\section{Surface Layer Trial}

\section{Requirement}

As WMA had previously been demonstrated to perform well in the less demanding conditions encountered at Adelaide Airport and Barrow Island Airport, a surface trial that included more demanding conditions was required. The trial was designed to be:

- Located within a runway. This allowed the surface to be grooved. Groove closure can be an issue for airport surface asphalt where less aged asphalt has suffered from groove closure under traffic due to viscous flow (Emery and Mihaljevic, 2008).

- Located with an intersection. This allowed exposure to slow turning aircraft. Groove closure and viscous flow are most likely to occur under slow moving and turning aircraft in intersections with taxiways and runway turning nodes.

- Exposed to heavy traffic. An airfield with a significant number of wide body (A330/B767) aircraft was required to exposure the surface to wheel loads exceeding 20 tonnes and tyre pressures exceeding 1,200 $\mathrm{kPa}$.

A location that was less critical to aircraft operations was also desired to allow access for monitoring and maintenance; in the unlikely event of poor performance. 


\section{Military Airfield WMA Trial}

A suitable location for a WMA trial was identified at the intersection of the secondary runway (also commonly used as a taxi-route) and the main taxiway at a military airfield located west of Brisbane in Queensland, Australia. This location met all of the above trial requirements. The airfield is home to the RAAF F/A-18 Hornet jet fighters as well as the KC30-B air-to-Air refuelling aircraft, which are based on a heavy lift variant of the A330.

The trial was performed in conjunction with the resurfacing of the secondary runway and other aircraft pavements in September 2013. The trial included 120 tonnes of WMA within the area of HMA overlay required under the broader project. This allowed a side-by-side comparison of HMA and WMA of otherwise identical design. As the trial was performed contiguously with the HMA project work, there was a transition between the HMA and WMA sections. This transition occurred as the asphalt temperature naturally decreased and stabilised after the foamed bitumen process was commenced and the mix temperature settings were modified. Approximately six weeks after the construction of the trial section, the surface was grooved. This delay was standard practice for Australian airports in order to allow the new asphalt to stiffen sufficiently to be grooved without plucking out of large aggregate particles. The trial area is shown in Figure 8.

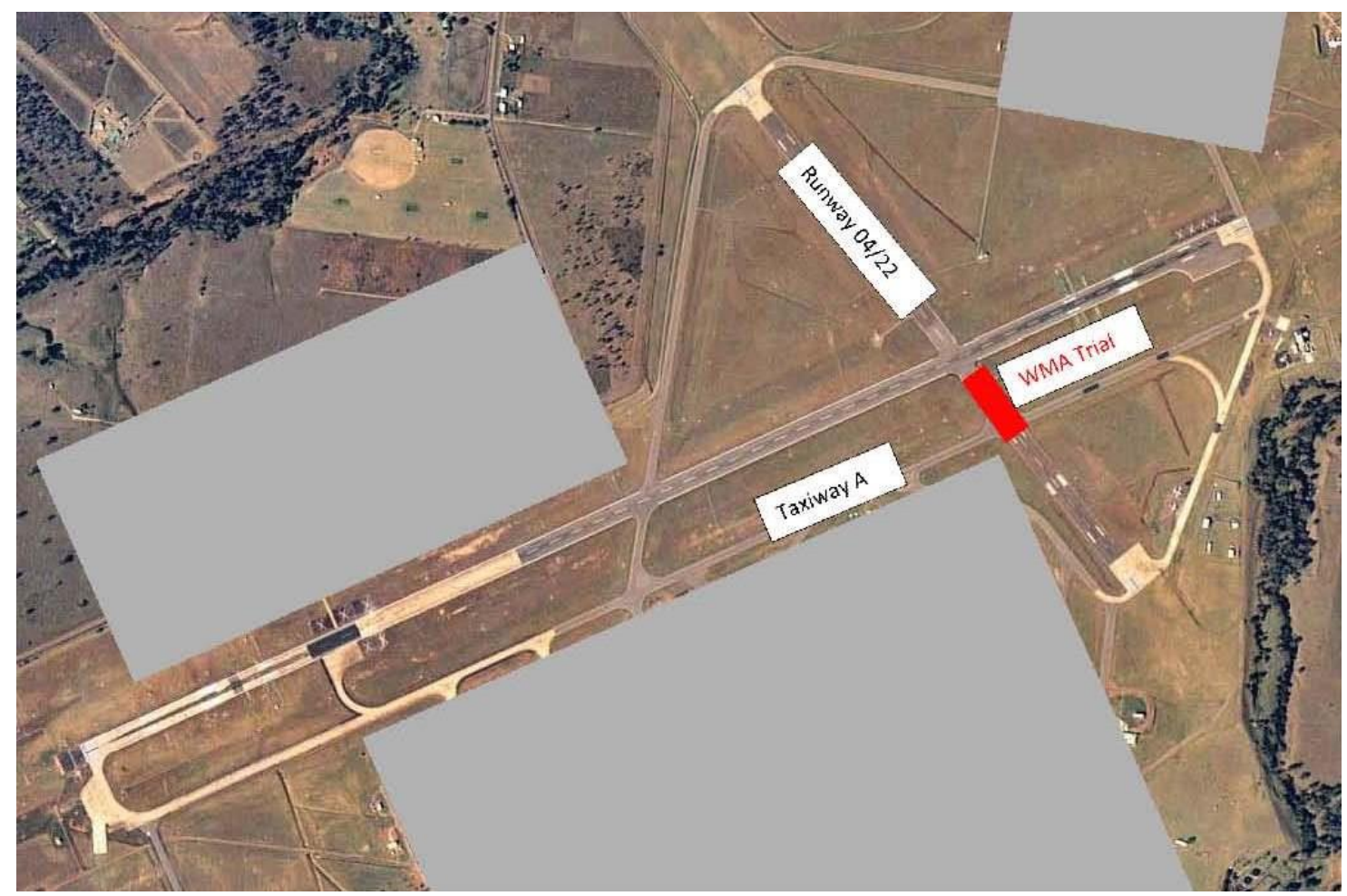

Figure 8 Military airfield trial location

For this work the HMA was manufactured at a target temperature of $170^{\circ} \mathrm{C}$ while the WMA was manufactured at a target temperature of $130^{\circ} \mathrm{C}$; with a constant production rate of 130 tonnes per hour. All asphalt for this project was manufactured in an Astec 170 tonne per hour mobile drum mixer equipped with an Astec foamed bitumen manifold for the production of WMA. The asphalt plant was located on-site, approximately $5 \mathrm{~km}$ from the trial location. The trial was constructed to a nominal 
thickness of $50 \mathrm{~mm}$ and the existing surface was textured with a cold milling machine, cleaned and tack coated ahead of the asphalt paving.

\section{Transition Time}

To determine the quantity of asphalt and length of time required for the production temperature to reduce and stabilise, the outgoing asphalt temperature was tracked from the time the plant was turned from HMA mode to WMA mode. As shown in Figure 9 it took 13 minutes (which equated to approximately 28 tonnes of asphalt production) for the temperature to drop and stabilise. Asphalt made during this transition phase was excluded from comparative testing and assessment, as was asphalt manufactured after the target production temperature was returned to $170^{\circ} \mathrm{C}$.

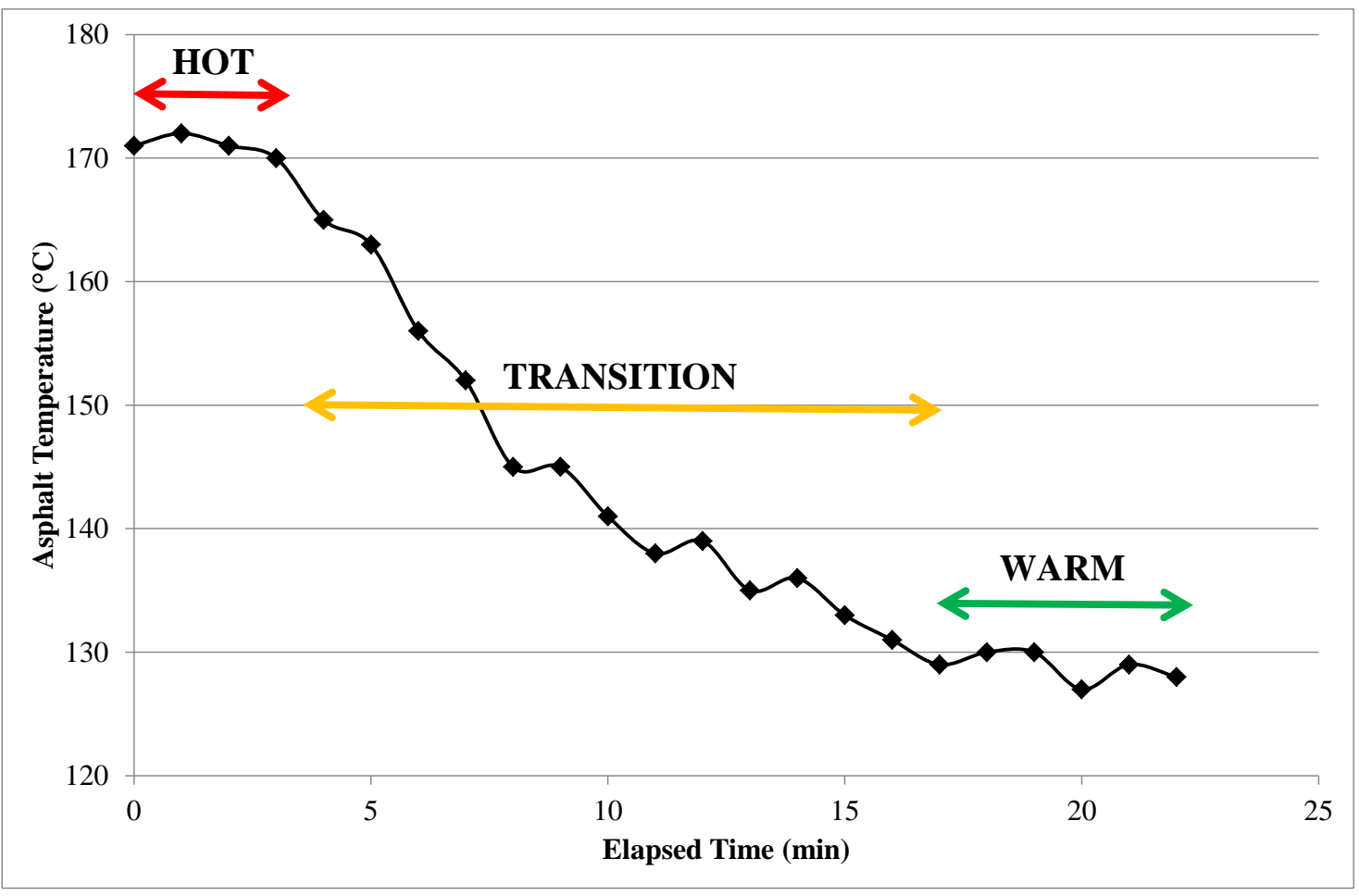

Figure 9 Temperature transition from HMA to WMA

\section{Laboratory Assessment}

During the mix design and production verification trials on site, HMA and WMA were produced and sampled. All of the standard specification production and verification testing was performed on both the WMA and the HMA samples. There was only minor difference between the HMA and WMA based on this data, as summarised in Table 6. The Relative Densities were slightly higher and air void contents slightly lower for the WMA. This was consistent with feedback from the construction crews that the WMA was easier to compact than the HMA despite the reduced mix temperature at the time of paving. The Marshall stability was slightly lower for the WMA, which was consistent with the results from Barrow Island, as was expected. 
Table 6 Production verification data from military airfield trial

\begin{tabular}{|c|c|c|c|}
\hline Property & Hot Mix & Warm Mix & Specification \\
\hline Moisture Content (\%) & $0.02-0.04$ & $0.03-0.04$ & $<0.15$ \\
\hline Flow (mm) & $2.4-2.9$ & $2.5-2.7$ & $<3$ \\
\hline Stability (kN) & $16.4-18.5$ & $15.7-17.7$ & $>11.5$ \\
\hline Air Voids Content (\%) & $4.0-4.4$ & $3.9-4.2$ & $3-5$ \\
\hline Relative Density (\%) & $97.8-98.8$ & $98.5-99.2$ & $97-100$ \\
\hline
\end{tabular}

Samples of HMA and WMA were also taken directly from the production plant for additional performance testing. The results are presented in Table 7. The results showed a minor decrease in the Resilient Modulus due to the reduced binder hardening at reduced production temperatures. The Wheel Tracking was slightly higher for WMA which would also reflect the reduced binder hardening. The result of $3.4 \mathrm{~mm}$ for WMA was, however, comparable to other airport asphalt mix results and was not considered to represent a performance risk. Otherwise the results were very consistent between HMA and WMA and were all comparable to historical HMA values measured on other Australian airport asphalt works of similar binder type and mix design.

Table $7 \quad$ Performance test data from military airfield trial

\begin{tabular}{|c|c|c|c|c|}
\hline \multirow{2}{*}{ Property } & \multicolumn{2}{|c|}{ Hot Mix } & \multicolumn{2}{c|}{ Warm Mix } \\
\cline { 2 - 5 } & Mean & Std. Dev. & Mean & Std. Dev. \\
\hline Resilient Modulus (MPa) & 3,552 & 72 & 2,786 & 55 \\
\hline Tensile Strength (kPa) & 957 & 21 & 940 & 19 \\
\hline Tensile Strength Ratio (\%) & 98 & N/A & 99 & N/A \\
\hline Wheel Tracking (mm) & 3.1 & N/A & 3.4 & N/A \\
\hline
\end{tabular}

The production and performance testing data collected from the WMA trial construction at the military airfield confirmed that the measurable properties of WMA ware not significantly different from those of HMA of identical design. All WMA production values were compliant with the overarching project specification and consistent with other airport asphalt values collected from various projects with similar mix designs over a number of years. However, monitoring of field performance remained necessary in order to assess the long term suitability of WMA as an alternate surfacing for Australian airport runways.

\section{Field Performance}

The field performance phase of this work was expected to span a number of years and was intended to confirm the long-term performance of WMA construction in the military airfield trial. The field performance assessment included two aspects: postconstruction coring for performance testing as well as ongoing visual inspection and condition monitoring. 


\section{Performance Testing}

A schedule of future coring of the WMA and adjacent HMA surface is planned. Each round of cores will be tested for:

- Resilient Modulus. Three cores from WMA and three from HMA.

- Wheel tracking. One core from WMA and one from HMA.

The cores will also be assessed for Relative Density prior to Resilient Modulus and Wheel Tracking. The TSR is not considered to be applicable to ongoing field performance assessment as the TSR test is a pre- and post-conditioning assessment and is intended to indicate future performance at the time of manufacture, rather than instantaneous condition at any given time during the service life.

The Relative Density, Resilient Modulus and Wheel tracking data will be logged over time and any change in the comparative performance of HMA and WMA will be used to further assess WMA as a runway surfacing in Australia.

The first field performance coring was performed around six weeks after construction, when the grooving was performed. The results are presented in Table 8 and show that the general difference between the WMA and HMA was evident in the Resilient Modulus results, but the magnitude of the different had decreased. It was observed that the relative densities had all approached $100 \%$ of that achieved in the laboratory, the Resilient Modulus had increased and Wheel Tracking had decreased. These are all normal trends following hot storage, paving, exposure to the prevailing weather and trafficking of an airport asphalt mix.

Table 8 Field performance test data from military airfield trial

\begin{tabular}{|c|c|c|c|c|}
\hline \multirow{2}{*}{ Property } & \multicolumn{2}{|c|}{ Hot Mix } & \multicolumn{2}{c|}{ Warm Mix } \\
\cline { 2 - 5 } & Mean & Std. Dev. & Mean & Std. Dev. \\
\hline Relative Density & $96.9-100.7$ & N/A & $98.6-101.2$ & N/A \\
\hline Resilient Modulus $(\mathrm{MPa})$ & 3,818 & 350 & 3,248 & 455 \\
\hline Wheel Tracking $(\mathrm{mm})$ & 2.1 & N/A & 2.2 & N/A \\
\hline
\end{tabular}

Future field performance coring is proposed to occur after 12 months. The period between subsequent field performance coring will then be assessed based on the changes in the data returned.

\section{Visual Assessment}

Concurrent with each round of field performance coring, a detailed visual inspection of the pavement will be performed. Where the period between field performance coring is greater than 12 months, a visual inspection will be performed at least every 12 months.

The WMA surface was inspected and June 2014 and found to be performing as expected. There was no detectable difference between the HMA and WMA sections. The warm joints between subsequent paving runs were generally well formed with very little segregation and in some cases were difficult to detect. 


\section{Conclusions}

WMA asphalt has been assessed in comparison to HMA via a number of projects at Australian airports since 2012. A formal trial was performed at a military airfield as part of a broader project in 2013. Comparison of production testing, performance testing of material sampled from the production plant and performance testing of cores obtained from the field, have all shown very similar results for WMA and HMA of identical mix designs.

The general and consistent trends in comparing WMA to HMA were:

- Resilient Modulus was moderately lower.

- Marshall Stability was moderately lower.

- Relatively Density achieved in the field was moderately higher.

These trends are consistent with reduced hardening of the asphalt binder during WMA production as a result of the reduced production temperature. Importantly, the moisture contents were not significantly different between WMA and HMA samples obtained from the production plant and the WMA complied with all conformance testing requirements of the current Australian airport asphalt specification.

It is concluded that, subject to ongoing monitoring and performance testing of the military airfield WMA trial, WMA was verified as a viable alternate surfacing material for Australian airport runways. This implies that the environmental, safety, quality and flexibility benefits of WMA can now be realised by Australian airports without concern regarding differential performance risk.

The use of WMA technology as a compaction aid is a significant benefit, allowing much greater haul distances from a fixed asphalt plant to be achieved than possible with a conventional HMA. This provides potential savings to airports associated with avoiding the establishment of a mobile asphalt plant on site. It also allows asphalt to be used for maintenance in smaller volumes than would be economical as well as allowing deep repairs to be affected in short work windows and the pavement returned to operational service more rapidly.

The acceptance of WMA as an alternate runway surfacing in Australia is also a step towards acceptance of the complimentary RAP technology. RAP has not yet been accepted by the Australian airport community, despite the significant quantity generated by the texturing and profiling of a typical runway during an asphalt overlay project.

\section{References}

Astec $2013<$ <ttp://www.astecinc.com/index.php?option=com_content\&view= article \&id=790:200-double-barrel-green-systems-for-astec \& catid=58:

latest-news\&Itemid=509>, accessed 6 July 2013.

Austroads 2006, Specification Framework for Polymer Modified Binders and Multigrade Bitumens, AP-T41/06, Austroads Project Number TT1133. 
Austroads 2007, Warm Mix Asphalt (WMA) Review, AP-T91/07, Austroads Project Number TT1220, November.

Austroads 2010, Review of Environmental Aspects of Warm Mix Asphalt, APT163/10, Austroads Project Number TT1454, July.

Chevron 2013, <http://www.chevronaustralia.com/ourbusinesses/gorgon.aspx>, accessed 10 July.

Davidson, JK, Tighe, S \& Croteau, JM, 2006, 'Paving the way to environmentally friendly pavements through innovative solutions', Proceedings of the Canadian Technical Asphalt Association Annual Conference, Charlottetown, Prince Edward Island, Canada.

EAPA 2003, Airfield use of Asphalt, European Asphalt Pavement Association, dated May, <http://www.eapa.org/sr_img/position_paper/airfield.pdf>, accessed 25 November 2013.

Emery, S \& Mihaljevic, I, 2008 'Accelerated load testing of asphalt mix design for heavy duty pavements in hot climates' Proceedings $23^{\text {rd }}$ ARRB Conference, Adelaide, Australia.

ERSA 2013, En Route Supplement Australia, dated 30 May, <http://www.airservices.gov.au/publications/aip.asp.>, accessed 2 August.

Hayward, BJ \& Pidwerbesky, B, 2009, 'CoolPave with LEA: low energy asphalt, the future of asphalt paving', Proceedings $10^{\text {th }}$ NZTA \& NZIHT annual conference, Rotorua, New Zealand, New Zealand Transit Authority.

Hurley, GC, 2006, Evaluation of new Technologies for use in Warm Mix Asphalt, a Thesis submitted for the partial award of Master of Science at the Auburn University, August 7.

Kristjánsdóttir, O, Muench, ST, Michael, L, \& Burke, G, 2007, 'Assessing the potential for warm mix asphalt technology adoption', Proceedings Transportation Research Board 86th Annual Meeting, Washington DC, USA.

Middleton, B, \& Forfylow, RW, 2008, 'An evaluation of warm mix asphalt produced with the Double Barrel Green process', Proceedings 7th International Conference on Managing Pavement Assets, Calgary, Canada, 15 April.

Ripoll, JO, \& Farré, CM, 2008, 'Evaluation of greenhouse gas emissions from the production of hot asphalt mixtures', Proceedings of the 4th Eurasphalt \& Eurobitume Congress, Copenhagen, Denmark.

Sasol Wax 2013, <http://www.sasolwax.us.com/sasobit.html>, accessed 10 July. 


\section{Acknowledgement}

The assistance of Chevron Australia and the Gorgon LNG Project, the owners of Barrow Island Airport, is acknowledged. As is the assistance of James Low of Adelaide Airport Limited. The Australian Department of Defence is also acknowledged for allowing the trial to be performed on their airfield.

My employer, Fulton Hogan, is acknowledged as the constructor of the warm mix asphalt at Barrow Island Airport, Adelaide Airport and the military airfield. 